\title{
Study of Parameters Affecting Temperature of Journal Bearing and Shaft in Sugar Mill
}

\author{
Kumpanat Sirivedin ${ }^{1, *}$, and Keittipong Choojit ${ }^{1}$ \\ ${ }^{1}$ TGGS, The Sirindhorn International Thai-German Graduate School of Engineering, King Mongkut's University of Technology North \\ Bangkok, Bangkok, Thailand
}

\begin{abstract}
In the sugar mill machine, equipment is operated under high temperature. This high temperature will affect to the roller shaft and journal bearing. Additionally, the equipment damages could be caused by the various factors that affected directly to roller shaft and journal bearing. In this research, the operations of equipments were modelled using the finite element analysis program (FEA), to determine the maximum temperature of the roller shaft and journal bearing after a specified period of time. An experiment with the physical roller shaft and journal bearing was carried out to obtain the actual temperature readings. Verification of the simulated results was performed by comparing the simulated values with the actual values obtained in the experiment. According to this research, the monitored parameters affected temperature and damages of the shaft and bearings during pressing oil from the hydraulic top cap. Finally, this research applied the FEA in conjunction with engineering and environmental management in sugar factory to reduces machine damange and to save energy during sugar mill operation.
\end{abstract}

Keyword. Sugar mill machine, Finite element analysis, Journal bearing.

\section{Introduction}

A sugarcane juice extraction is the first process in a raw sugar production to produce white or brown sugars and other by-products. It extracts sugarcane juice by crushing and breaking up hard nodes and flatten the stems by roller crushers. The process of extracting sugarcane juice by squeezing will create a pressure load on the surface area of the left and right journal bearings (Fig.1). It is pressed with a hydraulic cylinder through the top bearing with high pressure to the sugarcane in order to release as much as possible of the sweetness. Therefore, roller shafts and journal bearings are the important mechanical parts in the roller crusher (Fig. 1). When hydraulic pressure exceeds the critical value, work load or stress on journal bearing and shaft also exceed yield point and then plastic deformation occurs. Temperature on both journal bearing and shaft are accumulated and increases with hydraulic pressure. This will directly cause the damage on shaft and bearings and leads to failure of the roller crusher. Fig. 2 shows possible damage of journal bearing and shaft.

In a production line, if the roller shafts and journal bearings are damaged, the sugar production process will be interrupted immediately [1]. This affects on the production costs and waste of energy in the following evaporating process and drying process when roller crusher is under maintenance [2]. Therefore, this paper focused on parameters affecting temperature of shaft and journal bearing in the sugarcane mill machine by focusing on the critical point of shafts and bearings.

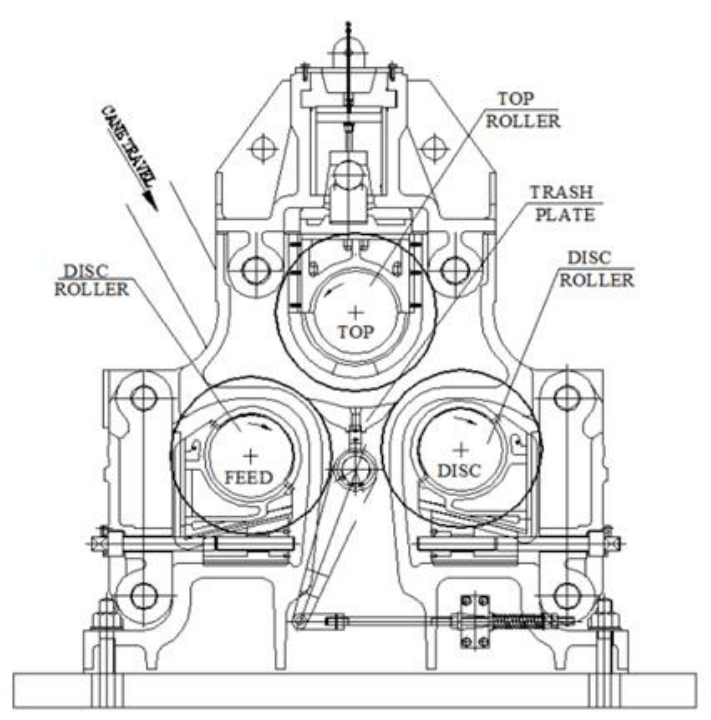

Fig. 1. Assembly of a conventional three-roller sugar mill.

\section{Materials and Methods}

In this research, the roller shaft and journal bearing were modelled using computer-aided design (CAD) software, SOLIDWORKS, and the finite element analysis program, ANSYS Workbench, to determine the maximum temperature of the roller shaft and journal bearing after a specified period of time [3]. Suggested geometry of shaft which showed minimum stress concentration was studied by Rathod et.al.[4]. Analytical

\footnotetext{
* Corresponding author: kumpanat.s@tggs.kmutnb.ac.th
} 
method and FEM were used to analyze the force on the support points according to the specified hydraulic pressure, in order to obtain the appropriate hydraulic pressure. The apply load come from the transferring pressure on the hydraulic top cap to the bearing [5]. The testing process can be divided into two steps.

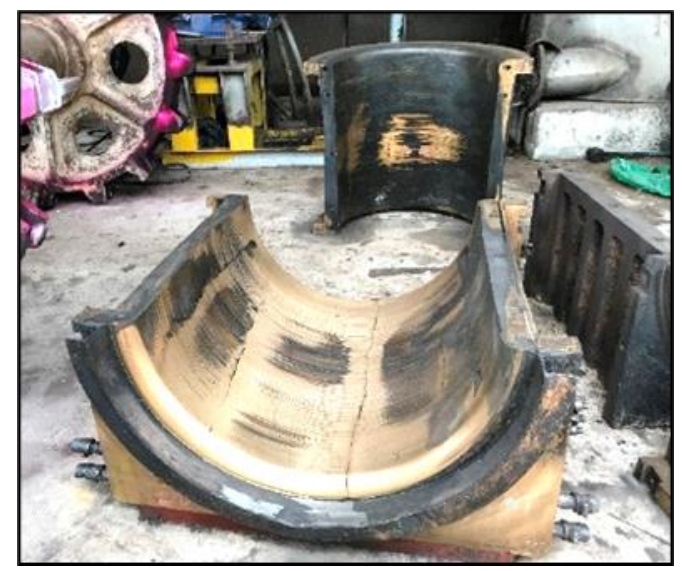

(a) Journal bearing failure

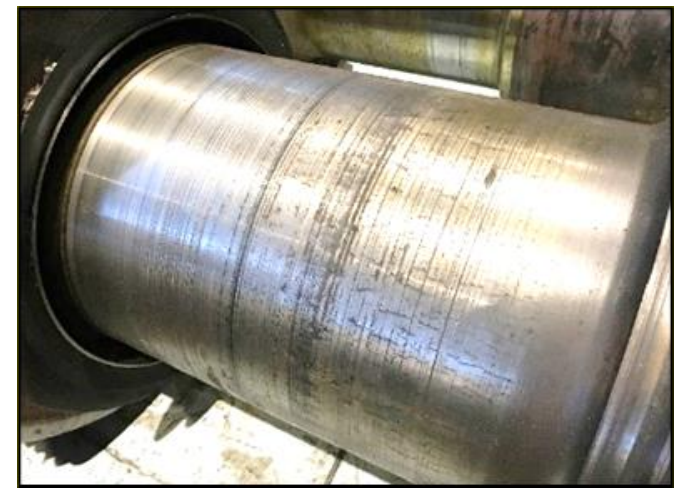

(b) Roller shaft failure

Fig. 2. The damages occur on (a) a journal bearing and (b) a roller shaft.

\subsection{Captions/numbering}

For thermal analysis of journal bearing, it is compulsory to collect the data for the bearing of the top roller (Fig.3).

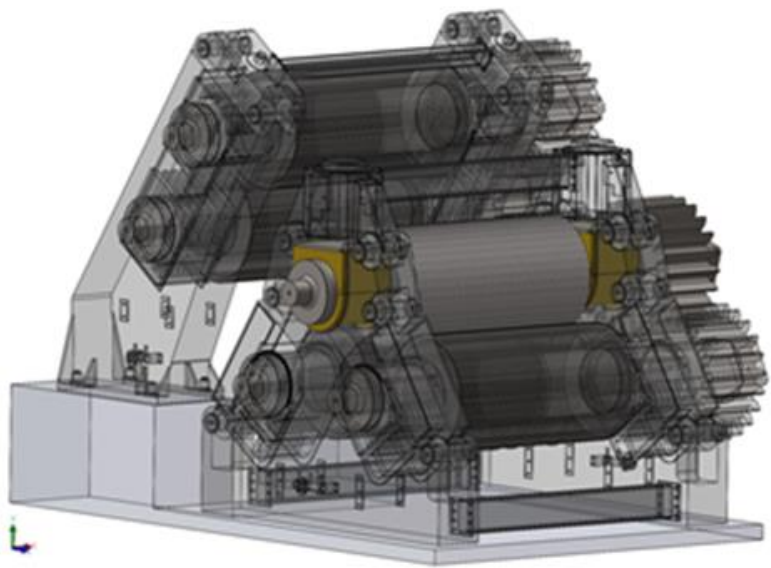

Fig. 3. The installation and position of top roller (3D-Model)
The specified pressure force in this study were 2600, 2800, 3000, and 3200 psi. The temperature distribution data was collected under specified pressure from the hydraulic top cap set by using an infrared thermometer during operating conditions at the shaft and journal bearing of sugarcane crushing machine (Fig.4). The collected values were plotted between temperature and time under the specified pressure.

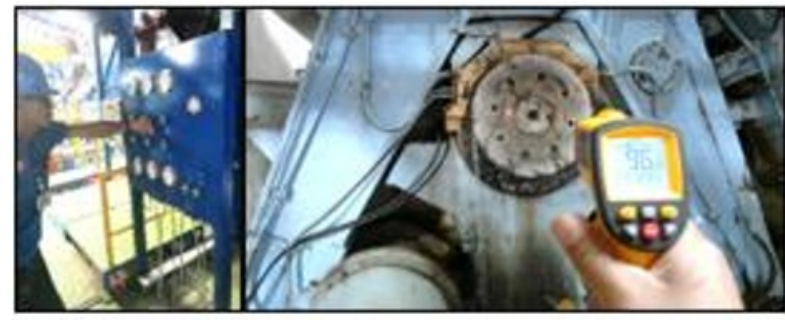

Fig. 4. Setting of the pressure load and the temperature measurement.

\subsection{The model analysis with the finite element method}

The finite element analysis (FEA) of the shaft and journal bearing were carried out. The simulation setup was as follows. The CAD model from SOLIDWORKS was exported into Ansys engineering simulation software, ANSYS Workbench, where the meshing and thermal simulation were carried out.

\subsubsection{Calculation for input parameters}

Input parameters for FEA were calculated by analytical method according to the technical data collected from the operating manual of the company. The technical data is given in Table 1.

Table 1. Technical specification of a conventional three-roller sugar mill.

\begin{tabular}{|l|c|}
\hline \multicolumn{1}{|c|}{ Details } & Value \\
\hline Power [p] (kw) & 900 \\
Roller speed [n] (rpm) & 5 \\
Roller diameter (mm) & 1250 \\
Shaft diameter at roller (mm) & 700 \\
Shaft diameter at bearing support (mm) & 620 \\
Shaft diameter at pinion (mm) & 625 \\
Pitch circle diameter of crown pinion (mm) & 1136 \\
Journal bearing size D x L (mm) & $620 \times 740$ \\
\hline
\end{tabular}

The top roller shaft (Fig. 5) is a critical component because the drive torque, hydraulic load, crushing load came from it. The forces acting on the mill roller increased shearing, bending, torsion and compressive stresses. Therefore, simple model of the forces acting on it must be considered [6]. 


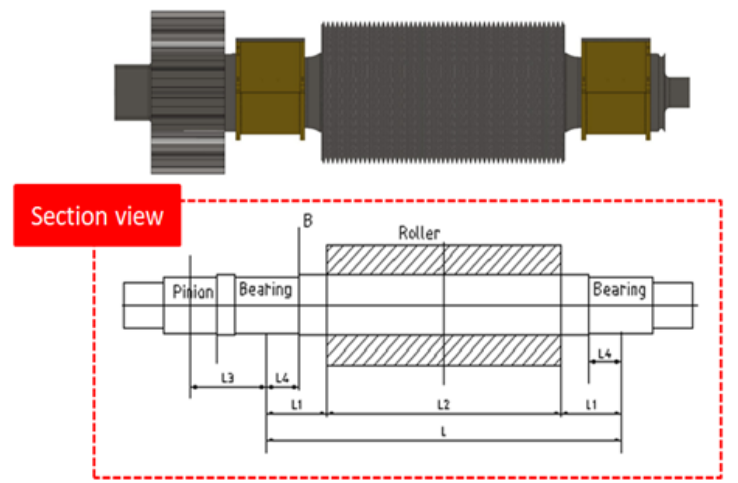

Fig. 5. Section view of the top roller shaft.

From Table 1, power $=900 \mathrm{kw}$ and speed $=5 \mathrm{rpm}$, a drive torque yields

$$
\text { Drive torque } \quad \begin{aligned}
=\frac{\text { Power } \times 9.55}{\operatorname{speed}(\mathrm{rpm})} \\
=1719.000
\end{aligned}
$$

$\mathrm{kN}-\mathrm{m}$.

The $50 \%$ of torque is taken by top roller.

$$
\begin{array}{rlrl}
\text { Torque of the top roller } & =\frac{\text { Drive torque }}{2} & \\
& =859.500 & & \text { N-m. } \\
& =859.500 \times 10^{3} & \mathrm{kN}-\mathrm{mm} .
\end{array}
$$

Tangential component (Horizontal) of force due to torque, $\mathrm{F}_{\mathrm{t}}$, where P.C.D is Pitch circle diameter of crown pinion $=940 \mathrm{~mm}$

$$
\begin{aligned}
\mathrm{F}_{\mathrm{t}}(\mathrm{Fph}) & =\frac{\text { Torque }}{(P . C . D) / 2} \\
& =1513.204
\end{aligned}
$$

Radial component (Vertical) of force due to torque, $\mathrm{F}_{\mathrm{r}}$, where pressure angle $(\theta)$ is $25 \mathrm{deg}$.

$$
\begin{aligned}
\mathrm{F}_{\mathrm{r}}(\mathrm{Fpv}) & =\mathrm{F}_{\mathrm{t}} \tan (\theta) \\
& =705.619
\end{aligned}
$$

$\mathrm{kN}$

Load of crushing from discharge roller acting at an angle of $53 \mathrm{deg}$.

$$
\begin{aligned}
\text { From right side } & =505.714 & & \text { tons. } \\
& =5057.143 & & \mathrm{kN}
\end{aligned}
$$

The vertical component of load

$$
\begin{aligned}
& =\text { Vertical load } x \sin (\theta) \\
\text { (Discharge Roller) } & =5057.143 \sin (53) \\
& =4038.814 \quad \mathrm{kN}
\end{aligned}
$$

The horizontal component of load

$$
\begin{aligned}
& =\text { Horizontal load } \mathrm{x} \cos (\theta) \\
(\text { Discharge Roller) } & =5057.143 \cos (53) \\
& =3043.465 \mathrm{kN}
\end{aligned}
$$

The load of crushing from feed roller acting at an angle of $55 \mathrm{deg}$.

$$
\begin{aligned}
& \text { From left side }=235.714 \quad \text { tons. } \\
& =2357.143 \quad \mathrm{kN}
\end{aligned}
$$

The vertical component of load

$$
\begin{aligned}
& =\text { Vertical load } x \sin (\theta) \\
(\text { Feed Roller }) & =2357.143 \sin (55) \\
& =1930.858 \quad \mathrm{kN}
\end{aligned}
$$

The horizontal component of load

$$
\begin{aligned}
& =\text { Horizontal load } x \cos (\theta) \\
(\text { Feed Roller) } & =2357.143 \cos (55) \\
& =1352.002 \quad \mathrm{kN}
\end{aligned}
$$

The weight of top roller is 32 tons., which acts downwards.

The total vertical load acting on the roller

$$
\begin{aligned}
& =\text { (Load from discharge roller }+ \\
& \text { Load from feed roller) - Weight of } \\
& \text { top roller }
\end{aligned}
$$$$
=5649.672 \mathrm{kN}
$$

The total horizontal load acting on the roller

$$
\begin{aligned}
& =\text { (Load from discharge roller - } \\
& \text { Load from feed roller) } \\
& =1691.463 \quad \mathrm{kN}
\end{aligned}
$$

The load of crushing acts on the surface of roller. So, it will be shown as uniformly distributed load (U.D.L) on the loading diagram.

Intensity of U.D.L. in vertical loading diagram

$$
\begin{aligned}
& =\frac{\text { Total vertical load due to crushing }}{\text { Length of shell of roller }} \\
& =2.456 \quad \mathrm{kN} / \mathrm{mm} .
\end{aligned}
$$

Intensity of U.D.L. in horizontal loading diagram

$$
\begin{aligned}
(\mathrm{Wh}) & =\frac{\text { Total horizontal load due to crushing }}{\text { Length of shell of roller }} \\
& =0.735
\end{aligned}
$$

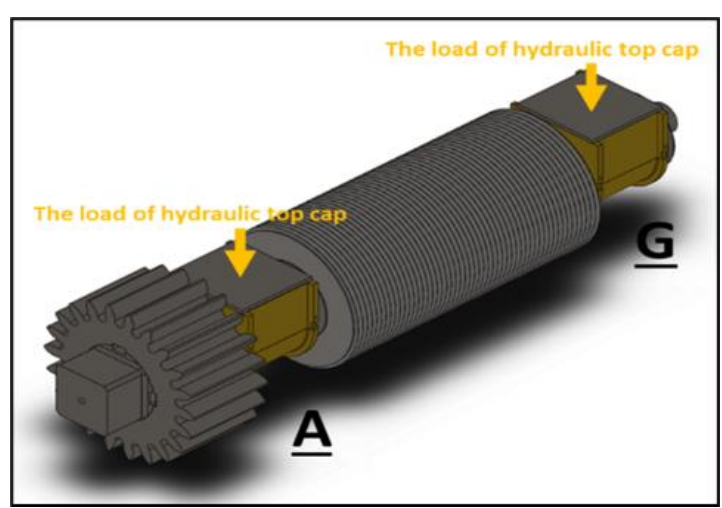

Fig. 6. Action force on the top roller.

The top roller was pressed with the hydraulic top cap at the top of the bearings on both sides (Fig.6). It worked by adjusting the hydraulic pressure from the power unit according to the desired value.

Diameter of hydraulic top cap $=460 \mathrm{~mm}$.

$$
\begin{array}{rll}
\text { Oil pressure } & =3000 \quad \text { psi. } \\
& =2.109 \mathrm{~kg} / \mathrm{mm}^{2}
\end{array}
$$


Total hydraulic load acting on the top roller

$=2 \mathrm{x}$ Area of piston $\mathrm{x}$ Oil pressure

$=7010.599$

Hydraulic load on each bearing $\left(\mathrm{F}_{\mathrm{h}}\right)$

$=\frac{\text { Total hydraulic load acting on the top roller }}{2}$
$=3505.299$

$=3505.299$

$\mathrm{kN}$

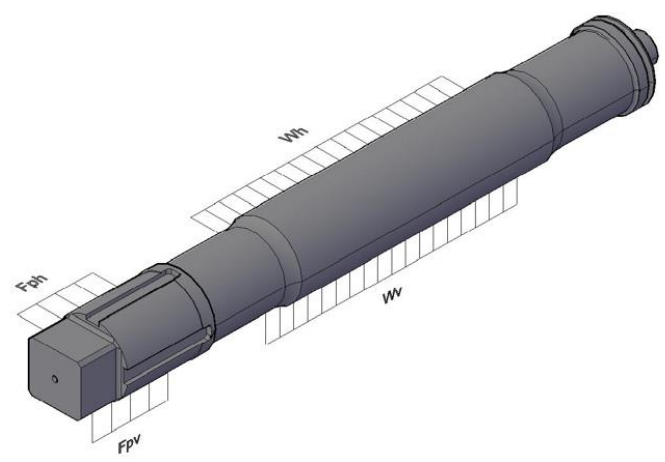

Fig. 7. Diagram of Load acting on the shaft.

Simple model analysis with equilibrium principle by determining the load of the force acting on the shaft was conducted. Two supports at points $A$ and $G$ in Fig. 6 were simplified into a simple model analysis with equilibrium principle (Fig.7). The simple model was later used to calculate the vertical and horizontal pressure load of journal bearing (Fig 8-9).

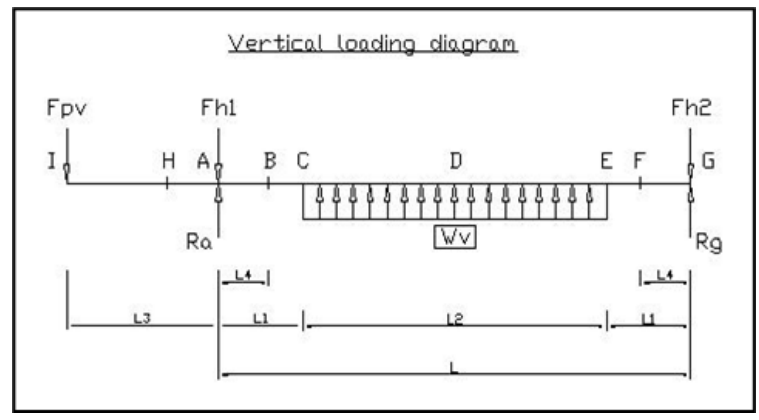

Fig. 8. Vertical loading diagram.

From Fig.5,

$$
\begin{array}{rlrl}
\mathrm{L} 1 & =650 & \mathrm{~mm} . \\
\mathrm{L} 2 & =2300 & \mathrm{~mm} . \\
\mathrm{L} 3=950 & & \mathrm{~mm} . \\
\mathrm{L} 4 & =375 & & \mathrm{~mm} .
\end{array}
$$

Fh1 and Fh2 are hydraulic load on each bearing

$$
=3505.299 \mathrm{kN}
$$

Vertical component of force due to torque

$$
\begin{array}{rll}
\mathrm{F}_{\mathrm{r}}(\mathrm{Fpv}) & =705.619 & \mathrm{kN} \\
\text { Intensity of U.D.L (Wv) } & =2.456 & \mathrm{kN} / \mathrm{mm} .
\end{array}
$$

$\mathrm{Ra}$ and $\mathrm{Rg}$ are reaction forces from bearing.

$$
\Sigma \mathrm{M}_{\mathrm{A}}=0 \text {; }
$$

$$
\operatorname{Rg}(\text { vertical }) \quad=494.258
$$

$$
\begin{aligned}
\Sigma F_{\mathrm{y}} & =0 ; \\
& \operatorname{Ra}(\text { vertical })=1572.287 \mathrm{kN}
\end{aligned}
$$

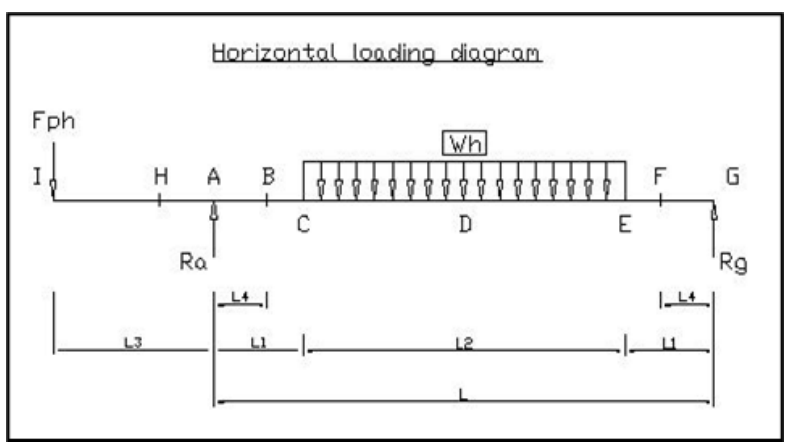

Fig. 9. Horizontal loading diagram.

Horizontal component of force due to torque

$$
\begin{array}{rll}
\mathrm{F}_{\mathrm{t}}(\mathrm{Fph}) & =1513.204 & \mathrm{kN} \\
\text { Intensity of U.D.L }(\mathrm{Wh}) & =0.735 & \mathrm{kN} / \mathrm{mm} .
\end{array}
$$

$\mathrm{Ra}$ and $\mathrm{Rg}$ are reaction forces from bearing.

$$
\begin{aligned}
& \Sigma \mathrm{M}_{\mathrm{A}}=0 ; \\
& \quad \operatorname{Rg}(\text { horizontal) }=446.414 \quad \mathrm{kN} \\
& \Sigma \mathrm{F}_{\mathrm{y}}=0 ; \\
& \quad \operatorname{Ra}(\text { horizontal })=2758.253 \mathrm{kN}
\end{aligned}
$$

Resultant of horizontal and vertical loading:

$\therefore$ Resultant reaction at ' $\mathrm{A}$ '

$$
\begin{aligned}
& =\mathrm{Ra}(\text { vertical })+\mathrm{Ra} \text { (horizontal) } \\
& =3174.909
\end{aligned}
$$

$\therefore$ Resultant reaction at ' $\mathrm{G}$ '

$$
\begin{aligned}
& =\operatorname{Rg}(\text { vertical })+\operatorname{Rg}(\text { horizontal }) \\
& =666.015 \quad \mathrm{kN}
\end{aligned}
$$

The determination result of the force on the shaft and the journal bearing under pressure load obtained from the hydraulic top cap pressure adjustment was found that the reaction force acting at the support points on both sides was different, which are shown in Table 2 . It was found that the reaction force at point $\mathrm{A}$ was significantly higher than that of the point G. Therefore, the reaction force under the specified pressure load at point A was used as the input in FEA in order to calculate the maximum stress and deformation.

Table 2. The reaction force between point A and point G.

\begin{tabular}{|c|c|c|}
\hline $\begin{array}{c}\text { The load of hydraulic top } \\
\text { cap/Oil pressure (psi) }\end{array}$ & $\begin{array}{c}\text { Resultant reaction } \\
\text { at 'A'(kN) }\end{array}$ & $\begin{array}{c}\text { Resultant reaction } \\
\text { at 'G'(kN) }\end{array}$ \\
\hline 2600 & 3042.581 & 540.214 \\
2800 & 3108.744 & 602.761 \\
3000 & 3174.909 & 666.015 \\
3200 & 3241.076 & 729.793 \\
\hline
\end{tabular}




\subsubsection{The model analysis}

Design the model (CAD model) was done by using computer-aided design with a mathematical model before entering the analysis process. Subsequently, a static analysis of top roller was done for observing maximum stresses and deformation. Static structural analysis was done using ANSYS Workbench [7]. Fig.10 shows a boundary condition in FEA model.

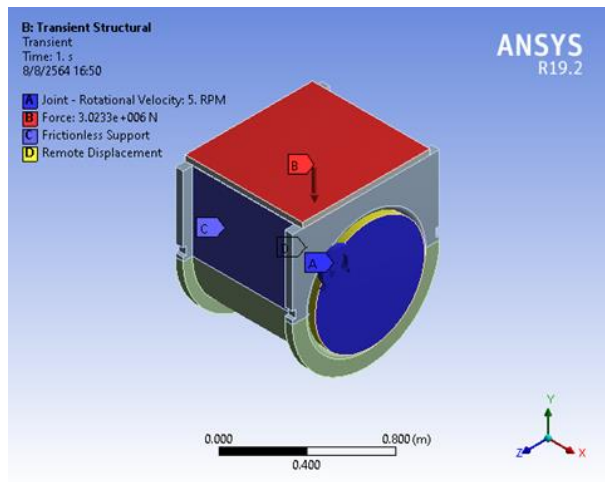

Fig. 10. Setting up boundary condition in details.

\subsection{Analysis of simulation}

The objective of performing the thermal simulation was to determine the maximum temperature and define its location (Figs.11-14).

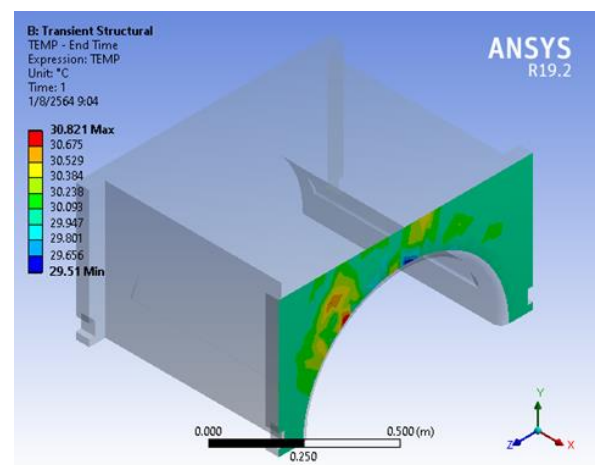

Fig. 11. Maximum temperature of journal bearing under pressure load 2600 psi

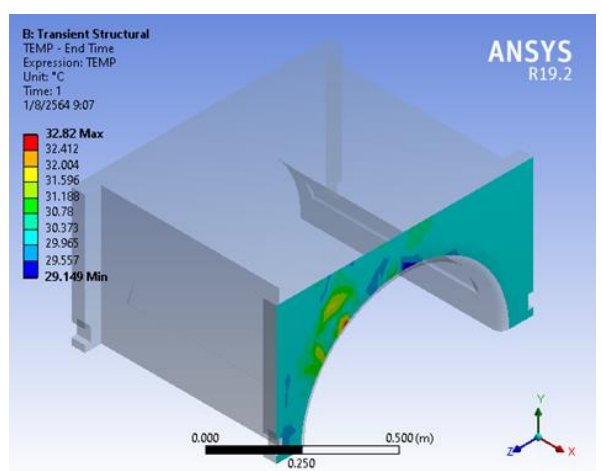

Fig. 12. Maximum temperature of journal bearing under pressure load 2800 psi.

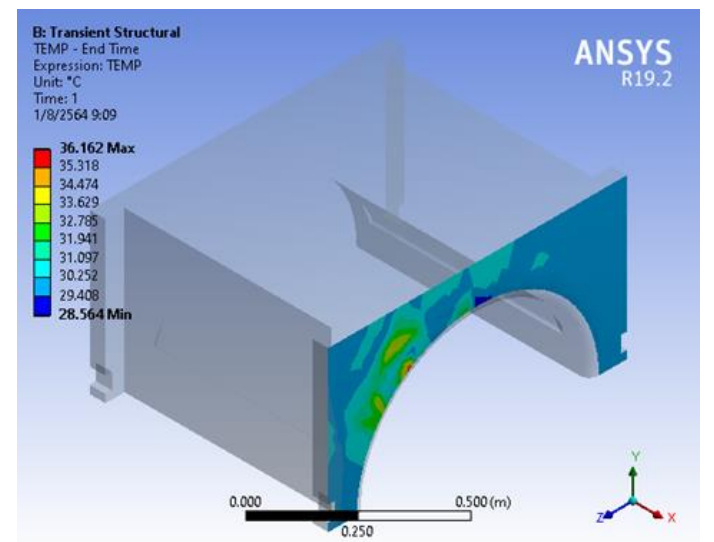

Fig. 13. Maximum temperature of journal bearing under pressure load 3000 psi.

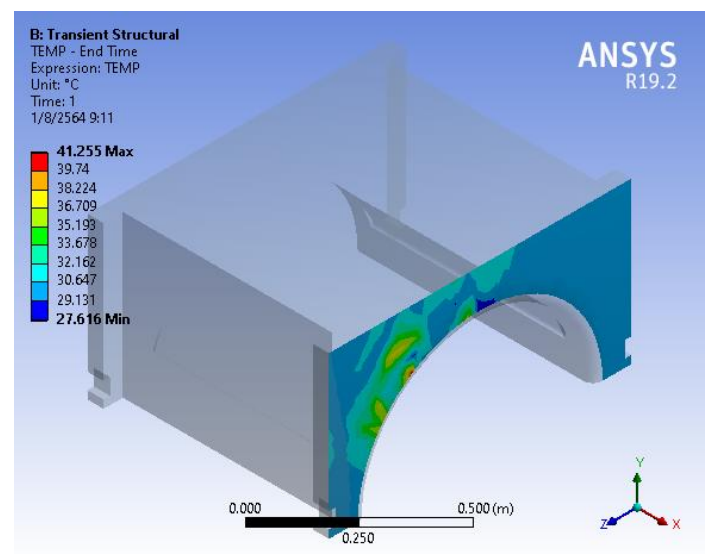

Fig. 14. Maximum temperature in journal bearing under pressure load 3200 psi.

\section{Results and Discussion}

The results from finite element method (FEM) with Ansys engineering simulation and $3 \mathrm{D}$ design software were compared with the experimental data. The results of surface temperature from FEM and experiments at pressure load of 2600, 2800, 3000, 3200 psi are shown in Figs.15-18, respectively.

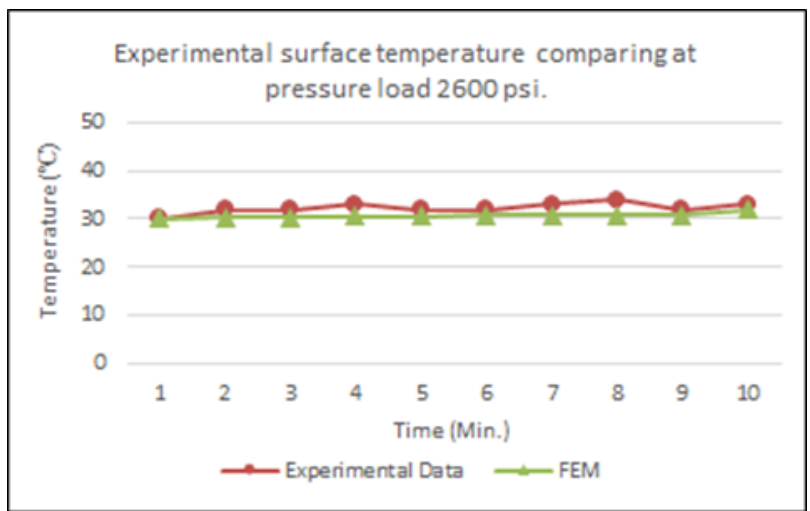

Fig.15. Comparison of temperature obtained from experimental data and FEM analysis at pressure load 2600 psi. 


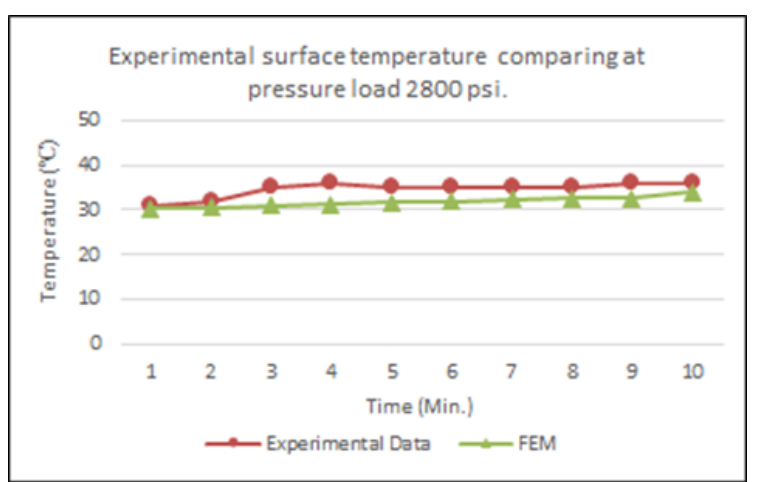

Fig.16. Comparison of temperature obtained from experimental data and FEM analysis at pressure load 2800 psi.

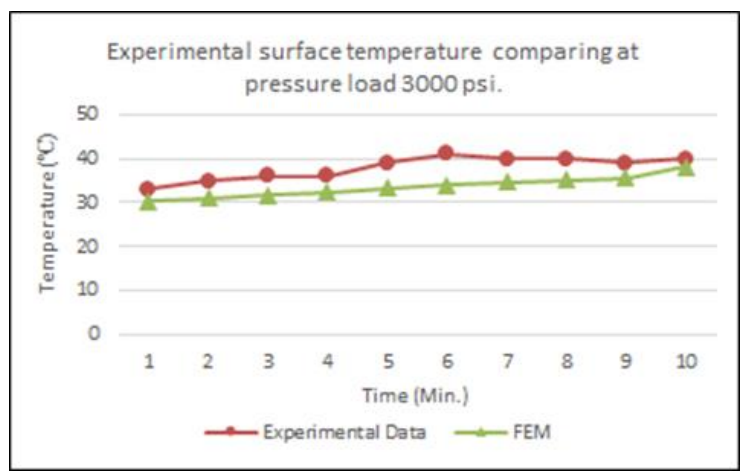

Fig.17. Comparison of temperature obtained from experimental data and FEM analysis at pressure load 3000 psi.

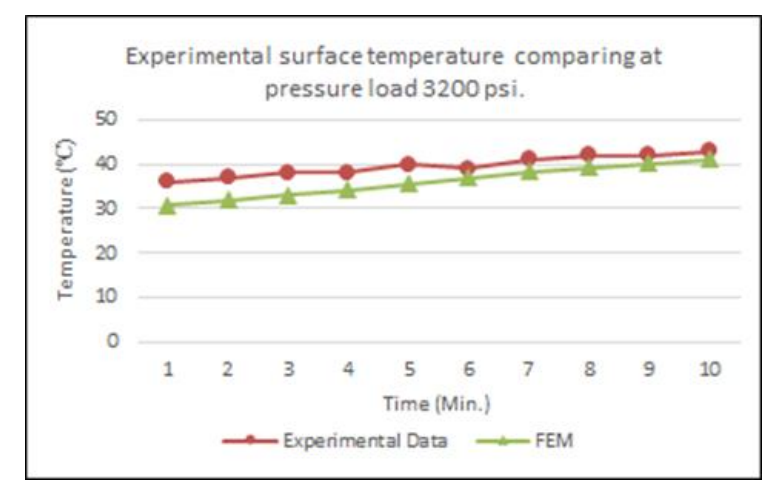

Fig.18. Comparison of temperature obtained from experimental data and FEM analysis at pressure load 3200 psi.

The results obtained from FEM were compared with the experiment results in order to validate the accuracy of the simulation results. It is observed that the simulated results were closely matched with that of the experiment results. The working temperature and the load of hydraulic top cap/oil pressure (psi) in Table 3 was plotted and shown in Fig.19.

Comparing with experiment and FEA results, the temperature difference are below $6 \% \quad(\sim 5.85 \%)$. Therefore, the FEA model in this study is valid and can be used to predict thermal stress and temperature of the journal bearing and shaft. Table 4 shows calculated temperature and Von-mises stress in various hydraulic pressure.
Table 3. The model analysis results.

\begin{tabular}{|c|c|c|c|}
\hline \multirow{2}{*}{$\begin{array}{c}\text { The load of hydraulic } \\
\text { top cap/Oil pressure } \\
\text { (psi) }\end{array}$} & \multicolumn{2}{|c|}{\begin{tabular}{c}
\multicolumn{2}{|c|}{$\left({ }^{\circ} \mathbf{C}\right)$} \\
Eorking Temperature
\end{tabular}} & \\
\cline { 2 - 3 } & $\begin{array}{c}\text { Experimental } \\
\text { data }\end{array}$ & FEM & \\
\hline 2600 & 34 & 32 & 5.88 \\
2800 & 36 & 34 & 5.56 \\
3000 & 41 & 38 & 7.32 \\
3200 & 43 & 41 & 4.65 \\
\hline
\end{tabular}

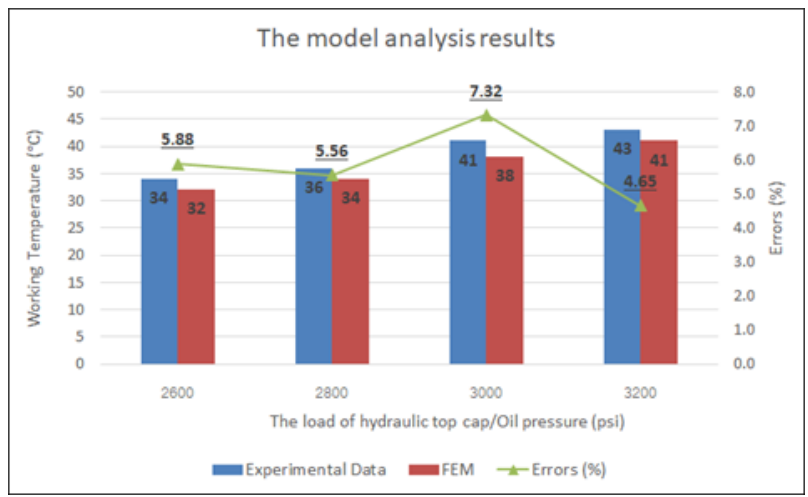

Fig. 19. Working temperature vs load of hydraulic top cap/oil pressure(psi) plot from FEM and experimental results.

Table 4. Results summary from finite element analysis.

\begin{tabular}{|c|c|c|c|c|}
\hline \multirow{2}{*}{$\begin{array}{c}\text { The load of } \\
\text { hydraulic top } \\
\text { cap/Oil pressure } \\
\text { (psi) }\end{array}$} & \multicolumn{2}{|c|}{ Temperature $\left({ }^{\circ} \mathrm{C}\right)$} & \multicolumn{2}{|c|}{$\begin{array}{c}\text { Von-mises stress } \\
\text { (MPa) }\end{array}$} \\
\cline { 2 - 5 } & min & max & min & max \\
\hline 2600 & 29.55 & 375.36 & 145.87 & 490.28 \\
2800 & 29.21 & 534.45 & 190.24 & 832.69 \\
3000 & 28.66 & 827.63 & 247.50 & 1200.50 \\
3200 & 27.94 & 1189.20 & 292.92 & 1535.60 \\
\hline
\end{tabular}

The finite element analysis (FEA) result found that the maximum stress value that caused damage to the initial bearing of 3000 psi. Therefore, the value of the analysis will be applied in the next working year. The load of hydraulic top cap/oil pressure adjustment does not exceed 3000 psi., it was reduced journal bearing damage. which are shown in Table 5.

Table 5. Results of the failure on the top journal bearing.

\begin{tabular}{|c|c|c|c|c|}
\hline \multirow{2}{*}{$\begin{array}{c}\text { No. of } \\
\text { trial }\end{array}$} & $\begin{array}{c}\text { Max. } \\
\text { pressure } \\
\text { used }\end{array}$ & \multicolumn{2}{|c|}{ No. of journal bearing } & \multirow{2}{*}{$\begin{array}{c}\text { Defect } \\
\text { (\%) }\end{array}$} \\
\cline { 3 - 4 } $1^{\text {st }}$ & $>3000 \mathrm{psi}$ & 10 & Failure & \\
$2^{\text {nd }}$ & $\leq 3000 \mathrm{psi}$ & 10 & 4 & 80 \\
$3^{\text {rd }}$ & $\leq 3000 \mathrm{psi}$ & 10 & 3 & 40 \\
\hline
\end{tabular}


This research starts at 1 st trial and applying the value of the analysis in 2nd and 3rd trials, which is reduced damage of journal bearing. This means the action force that affects to the damage of the shaft and bearings [8]. Finite element analysis can predict shaft and journal bearing damage from parameters that affects bearing operation such as speed, friction, clearance distance, and others [7]. These values can be used as indicator of damage through FEA analysis.

\section{Conclusion}

According to the research, the parameters affecting temperature and damage of the shaft and bearings was pressing oil from the hydraulic top cap, with a safe working value of less than 3000 (psi). This proves that the results of the experimental result are relatively close to the FEA analysis result and can be used in the other manufacturing processes. As a result of applying FEA analysis values to the device, it was found to reduce journal bearing damage and reduce waste of energy.

The FEA method has a few advantages, the results can be easily extracted from specific points and analysed with the tools available in the software. This reduces the time spent on data extraction and increased the overall project time efficiency. As a whole, the usage of computation simulation is an efficient and effective method of predicting the results in a thermal simulation.

\section{Acknowledgement}

This research was supported by M.W.A. Welding (Thailand) Company Limited.

\section{References}

1. S.M. Muzakkir, H. Hirani, G.D. Thakre, M.R. Tyagi, Tribological Failure Analysis of Journal Bearings Used in Sugar Mills, Engineering Failure Analysis, 18, (2011): 2093-2

2. A.S. Lee, Catalytic hydrogenation of liquid ketones with emphasis on gas liquid mass transfer, Ph.D. Dissertation, Texas A\&M University, (1999)

3. W.S. Rathod, C.T. Rathod, Design and Analysis of Two Roller Sugar mill using FEA Technique, International Journal of Scientific Engineering and Technology, 1, 3, (2012):148-152

4. N. Nao, M. Keiji, Stress Concentration Factors for Shoulder Fillets in Round and Flat Bars under Various Loads, International Journal of Fatigue, 19, 1, (1997): 75-84

5. E. Hugot, Handbook of cane sugar engineering third edition, Elsevier science publishers, (1986)

6. G.B. Richard, J.K. Nisbett, Mechanical Engineering Design. Eleventh Edition, McGraw-Hill Book Company, (2020)

7. S.M. Muzakkir, H. Hirani, K.P. Lijesh, Tribological Failure Analysis of Journal Bearings Used in Sugar Mills, Engineering Failure Analysis, 16, (2015): 36843-36850.

8. N.P. Narayan, Theoretical and Experimental Investigation on Tribological Failure of Journal Bearing of Cane Mills Used in Sugar Industry, (2019): 1-20 